\title{
Behavior Change or Empowerment: On the Ethics of Health-Promotion Strategies
}

Per-Anders Tengland*

\begin{abstract}
There are several strategies to promote health in individuals and populations. Two general approaches to health promotion are behavior change and empowerment. The aim of this article is to present those two kinds of strategies, and show that the behavior-change approach has some moral problems, problems that the empowerment approach (on the whole) is better at handling. Two distinct 'ideal types' of these practices are presented and scrutinized. Behavior change interventions use various kinds of theories to target people's behavior, which they do through information, persuasion, coercion and manipulation. Empowerment is a collaborative method where those 'facilitated' participate in the change process. Some ethical problems with the behavior-change model are that it does not sufficiently respect the right to autonomy of the individuals involved and risks reducing their ability for autonomy, and that it risks increasing health inequalities.

Empowerment, on the other hand, respects the participant's right to autonomy, tends to increase the ability for autonomy, as well as increasing other coping skills, and is likely to reduce inequalities. A drawback with this approach is that it often takes longer to realize.
\end{abstract}

\section{Introduction}

There are three main ethical issues related to public health (including health promotion). i) What are the (ultimate) goals for public health practice, i.e. what 'good' should be achieved? ii) How should this good be distributed in the population? iii) What means are we allowed to use in trying to achieve and distribute this good (Brülde, 2011b)? The last question is possibly the most important of the

\section{Background}

There are a great number of strategies to promote health in groups, communities and populations. We can legislate (Downie et al., 1996: 136, 137), e.g. prohibit certain things; we can use fiscal means to change people's behavior patterns (Downie et al., 1996: 52, 53), e.g. increase or reduce tax on certain items; we can use communication strategies (Finnegan and Viswanath, 2008), e.g. inform

This is a pre-copy-editing, author-produced PDF of an article accepted for publication in Public Health Ethics following peer review. The definitive publisher-authenticated version Tengland, Per-Anders. (2012) Behavior Change or Empowerment: On the Ethics of Health-Promotion Strategies, Public Health Ethics, 5, 140-153, is available online at: http://dx.doi.org/10.1093/phe/phs022 
people, or even manipulate them, e.g. through social marketing techniques (Cheng et al., 2011); we can try to persuade, induce or 'nudge' people into certain kinds of behavior (Buchanan, 2000; Thaler and Sunstein, 2008); we can cooperate with and 'facilitate' people (Rogers, 1961; Freire, 1972; Laverack, 2009) and we can change the environment (Baum, 2008: $389 \mathrm{ff}$. ), e.g. install speed bumps in order to reduce vehicle speed and thereby reduce the risk of accidents. These interventions, in general, consist of top-down strategies, where a government, ministry, county council or municipality decide to change some factors in order to reduce the risk of illness, disease or injury, or augment the likelihood of increasing or sustaining population health (Verweij and Dawson, 2007).

However, not all strategies are top-down. Some are 'local', which means that they involve professionals meeting people eye-to-eye. Mostly, these interventions are concerned with people, groups or communities that are vulnerable in one way or another. Roughly, the individuals and groups that might need support fall into two overlapping categories. Their problems might have to do with their living conditions, such as poverty, marginalization, poor housing and unemployment, which put them at a risk of developing illness or disease. Or they have a 'risk behavior' or a 'lifestyle' problem, such as smoking, drinking alcohol, using drugs, engaging in unsafe sex, or being overweight or obese. Research shows that if one belongs to a vulnerable group, one is more likely to have lifestyle problems (Marmot and Wilkinson, 1999; Marmot, 2004; Baum, 2008), and most lifestyle problems, save for alcohol consumption, are more common in vulnerable and low socio-economic groups (Pellmer and Wramner, 2009).

Few population strategies directly increase or sustain the health of the population (Nordenfelt, 1991; Tengland, 2010).1 Most of them are indirect or instrumental, where improvements in (future) health are achieved through some other change or activity, e.g. when an information campaign makes people eat more fruit and vegetables, which leads to better overall health, or when the construction of a new bike lane makes people bike to work, thereby increasing their general fitness. As the examples show, some of these indirect strategies have to do with internal changes (within the individual), and some with external (environmental) changes.

Among the general strategies that try to deal with these kinds of problems, we find two approaches, namely behavior change and empowerment. Both these kinds of approaches purport to help people achieve better health. A major difference is that the empowerment approach can only be used in 'local' interventions, since it requires collaboration with the individuals involved, whereas behaviorchange strategies can be used in both top-down and local interventions. Despite their common general aim, i.e. sustained and increased health, both have their specific approach or 'tools'. These approaches and these tools might partly overlap, but they also seem to come into conflict.

\section{Aims and Method}

The aims of this study are to present the behavior-change approach and display some of its moral disadvantages, to introduce the empowerment approach as an alternative strategy and show that it

This is a pre-copy-editing, author-produced PDF of an article accepted for publication in Public Health Ethics following peer review. The definitive publisher-authenticated version Tengland, Per-Anders. (2012) Behavior Change or Empowerment: On the Ethics of Health-Promotion Strategies, Public Health Ethics, 5, 140-153, is available online at: http://dx.doi.org/10.1093/phe/phs022 
can handle most of the problems of the first approach and, finally, to discuss some of the potential problems with the empowerment approach and how they can be dealt with. Several ethical arguments will be given, but primarily they will be rights-based and consequentialist and, to some extent, egalitarian ones.

There are obviously many different versions of these two approaches, some of which might make them seem more or less identical. In order to make behavior change and empowerment stand out as real alternatives, I have created two distinct 'ideal types' of these practices (Ringer, 1997). As to empowerment, I will use my own earlier analysis of the concept (Tengland, 2008). Concerning the behavior-change approach, I will state what I believe to be some of its core characteristics, so that it becomes a clear alternative to the empowerment approach. Scientific literature has, then, been studied and analyzed in order to produce these two 'ideal types'.

\section{The Two Approaches to Health Promotion}

In the following sections I will present the two approaches, and then turn to a discussion and evaluation of them. Before that, in order to understand what the means used are aimed at, we need to know more about the aims of the two approaches discussed. Their main general aim (in this context2) is health. 3 The instrumental aims of the two approaches, purporting to lead to better health, are somewhat different. The instrumental aim in one case is changing health-related behavior or lifestyle, and in the other, helping people acquire better control over the determinants of their health (Tengland, 2011). As we shall see, there are also lower-level instrumental goals targeted, such as beliefs, attitudes, skills or environment changes.

\section{Means to Behavior Change}

In brief, professionals working with the behavior-change approach want to influence (other) people to change their health-related behavior, be it to stop smoking, eat less, eat better, exercise more, drink less alcohol, use condoms, abstain from unsafe sex, drive more carefully, use bike helmets or stop using drugs (Buchanan, 2000: 41; Earl and O'Donnell, 2007: 81; Holland, 2007: 112 ff.). This is sometimes expressed as wanting to make people change their 'lifestyles' (Lalond, 1974; Earl and O'Donnell, 2007: 81, ff.; Holland, 2007: 112 ff.).4 According to Glanz et al. (2008), an important goal of research programs has been 'to identify and test the most effective methods to achieve healthbehavior change' (p. 16). This is not a new thought. In 1976, Simonds defined health education as the practice of 'bringing about behavioral changes in individuals, groups and larger populations...to behaviors that are conducive to present and future health' (in Glanz et al., 1997: 7). There is, furthermore, a striving to find 'effective methods' (Glanz et al., 2008: 16) and to 'develop techniques' (Glanz et al., 1997: 26) that have 'powerful effects' (Glanz et al., 2008: 4), in order to achieve behavior change, and 'reduced resistance to change' (Glanz et al., 1997: 26).

David Buchanan mentions four kinds of (more or less problematic) strategies that the behaviorchange approach uses to influence people to change their behavior: behaviorist conditioning, e.g. through 'rewards' and 'punishment'; communicative persuasion, e.g. through subliminal information

This is a pre-copy-editing, author-produced PDF of an article accepted for publication in Public Health Ethics following peer review. The definitive publisher-authenticated version Tengland, Per-Anders. (2012) Behavior Change or Empowerment: On the Ethics of Health-Promotion Strategies, Public Health Ethics, 5, 140-153, is available online at: http://dx.doi.org/10.1093/phe/phs022 
or 'scare' campaigns; group pressure, e.g. through 'meeting strategies' where people are influenced to abstain from certain kinds of behavior; and direct instrumental power, e.g. through prohibitions or authority (Buchanan, 2000: 35). Furthermore, a variety of different theories (or models) are used to underpin the various kinds of strategies to change behavior or lifestyle (Buchanan, 2000).

What is common for many of these strategies is that they often use some kind of social psychological theory, e.g. the health belief model, the theory of reasoned action, or the social cognitive theory (Buchanan, 2000), in order to achieve their ends. Other theories used are the transtheoretical (stages of change) model, the diffusion of innovation theory, and the communication-behavior change model (Glanz et al., 2008; Nutbeam et al., 2010). These theories and models are used as tools for targeting specific kinds of behaviors in order to change them. Thus, they are instrumental in influencing and changing the health-related behavior of groups of people (Buchanan, 2000: 14, ff.; Nutbeam et al., 2010: 9). Several authors and theoreticians emphasize their practical utility (Glanz et al., 2008: chs. 2, 22). '[T] heories can help us to understand what methods we can use', and clarify 'the most effective means of achieving change' (Nutbeam et al., 2010: 3), and according to Bandura, the ultimate test of theories is 'when they indicate methods that are "capable of effecting significant changes in human affect, thought, and action"' (in Maibach and Parrott, 1995: viii.).

Health-related behavior change is the primary instrumental aim, but the immediate targets are typically psychological or cognitive factors, such as beliefs, attitudes and self-efficacy, and to a lesser extent the environment (Bandura, 1982; Downie et al., 1996: 29-31; Tones and Green, 2004: $80 \mathrm{ff}$;; Baum, 2008). The psychological or social environment is sometimes also targeted, as with social cognitive theory (Nutbeam et al., 2010: 17), but traditionally, the physical, social and cultural environments receive little attention (Baum, 2008: 457).5

Let us look closer at how the theories work. First, they accept a teleological scientific model of how individual behavior should be explained. One elaborate version of this kind of 'practical syllogism' is presented by Rosenberg (2008: 35). In order to explain why a (rational6) agent acts (does, or refrains from doing, something), the following requirements have to be met: 1 : the individual $X$ wants (in a strong sense) $Y$ (e.g. to lose weight); 2: $X$ believes that doing $Z$ (swim regularly) is a means to bring about $Y$ under the circumstances; 3 : there is no action believed by $X$ to be a way of bringing about $Y$ that under the circumstances is more preferred by $X$ (e.g. cycling); 4 : $X$ has no wants (e.g. playing computer games) that override $Y ; 5: X$ knows how to do $Y$ (can swim); and $6: X$ is able to do $Y$ (is healthy enough to swim). Because 'ability' sometimes includes 'opportunity' and sometimes excludes it, it is important to distinguish between them, especially since the distinction is crucial in discussing health promotion. All the above-mentioned premises might be fulfilled, but there might not be a possibility to act. For example, having decided to exercise through swimming in the public swimming pool, the person might find that the pool is closed for maintenance. I will therefore add 7:

opportunity as a final requirement of the model, and reserve ability for the relevant internal features needed to perform the action.

This is a pre-copy-editing, author-produced PDF of an article accepted for publication in Public Health Ethics following peer review. The definitive publisher-authenticated version Tengland, Per-Anders. (2012) Behavior Change or Empowerment: On the Ethics of Health-Promotion Strategies, Public Health Ethics, 5, 140-153, is available online at: http://dx.doi.org/10.1093/phe/phs022 
All of the above-mentioned social, psychological and other theories (or models) use this way of reasoning, albeit in more rudimentary forms [steps 3 and 4 are usually not mentioned, but have to be considered, since there are usually both alternative action strategies and overriding wants to take into account. Real opportunity (7) is also often ignored in these models, even though 'perceived' opportunity might be mentioned]. The teleological model is used for explaining action, but also for predicting and influencing action. The interventions target one or several of these requirements in order to achieve health-related change, such as trying to influence attitudes to wants through advertising (making 1 or 4 more, or less, likely), changing beliefs through information (2, 3 and 5), or strengthening self-efficacy through discussion groups ( 1 , and perhaps 6$)$.

\section{Empowerment as a Goal and as a Process}

The term 'empowerment' has two distinct meanings, one referring to a state of the individual, group or community (and a goal to be achieved in empowerment projects), and the other referring to the process (or means) to attain the goals (empowerment in the first sense) sought (Tengland, 2008). The first meaning will not concern us much here, but it still needs to be mentioned. Empowerment as a state concerns the individual's (or group's) control over her (their) life. More precisely: to be empowered is to have control over the determinants of (i.e. those factors that contribute to) one's quality of life. Because we are within a health promotion context, we are not interested in all kinds of control, but mainly in health-related control (Tengland, 2007). The ability for autonomy (selfdetermination) has a central place in this approach, because the higher it is, the better the individual will be at determining her authentic goals (Tengland, 2007, 2008).7

The second definition of empowerment (as a process) is more important for us here, since it has to do with the means of working toward health, empowerment and quality of life. Empowerment as a process (a means) is directly related to professional practice on the 'local' level, i.e. working together with the people involved. The concept is found in literature discussing civil rights movements in the 1960s and onwards (Rissel, 1994; Starrin, 1997; Craig et al., 2011), and the idea is inspired by, among others, Paolo Freire (1972) and Carl Rogers $(1961,1977)$.

Empowerment as a process is about letting the client, group or community have as much control as possible over the change processes they are involved in (Rogers, 1961; Freire, 1972; Tengland, 2008; Laverack, 2009). They should therefore actively participate in the problem formulation, the solutions to the problems and the actions performed to solve them. The professional should primarily be an enabler or a facilitator.

As distinct from the behavior-change approach, which primarily relies on cognitive or behavioral psychology, the empowerment approach is based on humanist-existentialist ideas about human nature. One difference is that the empowerment approach emphasizes that individuals themselves have the (internal) means to change and develop in a positive direction. Given psychological conditions that include empathic listening, nonjudgmental attitudes, genuine participation on the part of the professionals and enabling dialogical conditions, as well as (external) opportunities, the

This is a pre-copy-editing, author-produced PDF of an article accepted for publication in Public Health Ethics following peer review. The definitive publisher-authenticated version Tengland, Per-Anders. (2012) Behavior Change or Empowerment: On the Ethics of Health-Promotion Strategies, Public Health Ethics, 5, 140-153, is available online at: http://dx.doi.org/10.1093/phe/phs022 
individuals or groups involved will empower themselves (Rogers, 1961, 1977; Freire, 1972;

Wallerstein and Bernstein, 1988; Tones and Green, 2004; Laverack, 2009). No persuading, rewarding, punishing, coercing or manipulating is needed.

As to the teleological model mentioned earlier, it is not always explicitly utilized in the empowerment approach, although 'folk psychology' (i.e. Rosenberg's model) is implicitly taken for granted, since the approach has to take beliefs, wants, knowledge, etc. into account at some point. The crucial difference is that the empowerment approach focuses less on (influencing) beliefs and wants (1-4), and much more on (increasing) ability, e.g. on generic skills development (Freire, 1972; Laverack, 2009), and (creating) opportunity (5-7) (Laverack, 2009). No doubt, this will have effects on both beliefs and wants.

\section{Ethical Problems with the Behavior-Change Approach}

In the following sections, we will look at some ways in which the behavior-change approach may be criticized, namely in that it does not respect the autonomy and the dignity 8 of the individual (or group), in that it risks harming the individual, and that it risks increasing health inequalitites.

\section{Problems with the Right to Autonomy and Equality}

As we saw, most behavior-change projects have narrow lifestyle goals, such as smoking cessation or increased physical activity, and they use various means to influence the target group, sometimes informing, persuading, coercing, or manipulating the individuals or groups targeted, in order to reach these goals. Some of these strategies do not sufficiently respect the indivdual's right to autonomy (self-determination) and liberty, i.e. the right to decide over one's life, and over specific issues concerning that life. Others are less problematic and can be defended on other moral grounds.

Let us look at some strategies. Informing people about health threats or health benefits does not appear to involve any major ethical problem, because if the strategy is successful, it seems to be because the individuals or groups themselves found the information useful or persuasive and chose to act on it. One problem, however, is that different groups are, to a varying degree, likely to understand and act on the information they get. More vulnerable groups, e.g. low socio-economic groups, seem to be less prone to act on health advice than less vulnerable groups (Baum, 2008: 475). One reason for this might be that acting on the information requires some sacrifices, e.g. in terms of time, effort or money. Another reason might be low 'health literacy', i.e. low motivation or capacity to access, understand or use health-related information (Nutbeam et al., 2010: 37, 38). It is, then, possible that the information will not benefit these vulnerable groups. Thus, even if some people will benefit from information campaigns, and the average (aggregated) health might increase in the population, there is also a risk of increasing health inequalities (Brülde, 2011b; Daniels, 2011; Wilson, 2011). This should, of course, not make us conclude that health information is not important. It should rather make us aware of the fact that other complementary measures are necessary in order to reduce health inequalities.

This is a pre-copy-editing, author-produced PDF of an article accepted for publication in Public Health Ethics following peer review. The definitive publisher-authenticated version Tengland, Per-Anders. (2012) Behavior Change or Empowerment: On the Ethics of Health-Promotion Strategies, Public Health Ethics, 5, 140-153, is available online at: http://dx.doi.org/10.1093/phe/phs022 
In some of the 'local' cases, the professional takes the opportunity to bring up a topic that she feels is relevant for the individual (or group), so-called 'opportunistic' health information, as well as asking questions about health-related behavior (Nikku, 1997; Fitzpatrick, 2001).9 One moral objection to this practice is that it might be thought to be an infringement of the individual's right to privacy (autonomy) to be informed about lifestyle matters she did not ask for (implying a problem), and furthermore, to be asked about her habits, or 'lifestyle'. Such questions might cause embarrassment, unease, worries, shame and feelings of guilt, and thus, compromise her dignity.10 This might, furthermore, lead to feelings of stigmatization, a risk that also has to be taken into account in topdown projects, such as addressing problems with obesity (French et al., 2009: 146; Loss and Nagel, 2010: 60), or parents who smoke (Grier and Bryant, 2005: 335).

Persuasion, and especially the use of authority, is another (similar) problem that might appear in face-to-face encounters, especially when the agenda is set by the professional (Nikku, 1997). Authoritative persuasion here means that a person with real or perceived high status (Wrong, 2004: $35 \mathrm{ff}$.), e.g. a doctor, a community nurse or a health promoter, tries to talk or pressure someone into a change of behavior -i.e. basically influencing aspect 1 (wants) in Rosenberg's scheme-where there is some initial resistance on the part of the individual (or group). This might happen opportunistically, but perhaps more often when a person or a group is invited to discuss a predefined topic or problem, and has little influence on the agenda. For instance, a person might be given the opportunity to discuss smoking cessation or weight loss, but not to discuss other, more pressing, health-related issues, such as housing problems, lack of education or child care. It becomes an ethical question when the issue or problem, and how it should be dealt with, is wholly determined by the professional, without taking into account what the individual (or group) wants, and pressurizing her (or them) into complying with the advice given (Nikku, 1997). In these situations, there is, thus, a mixture of paternalism (i.e. 'to impose limitations on someone or to require actions by someone for his or her own good'; Bayer et al., 2007: 86.) and authority that puts the individual in a weak position. Thus, it does not respect her right to autonomy, and it risks making her feel offended, vulnerable and powerless (Nikku, 1997; Buchanan, 2000; Holland, 2007).

Coercion and manipulation may constitute more serious ethical problems, but such measures mostly appear in top-down strategies, such as legislation and social marketing. Some kinds of coercion are, however, morally unproblematic. All governments act paternalistically, often for good reasons. Much of this is done by coercing people through legislation (legal force), e.g. to wear seat belts, not to drink and drive, and not to use narcotics. In liberal welfare societies, there is, however, a suspicion about too many restrictions (Mill, 1859; Holland, 2007). We do not, for example, prohibit the use of sugar, or smoking (unless in public areas), even though we know they are bad for people's health. There is a tension between the state's interest in intervening in order to protect the population (from itself) and people's right to do what they themselves find best (Holland, 2007: 37-40). Thus, using coercive means to change health-related behavior is not always a problem. The less important (or the more trivial) the infringement and the greater the health gain, the less problematic the project, especially if

This is a pre-copy-editing, author-produced PDF of an article accepted for publication in Public Health Ethics following peer review. The definitive publisher-authenticated version Tengland, Per-Anders. (2012) Behavior Change or Empowerment: On the Ethics of Health-Promotion Strategies, Public Health Ethics, 5, 140-153, is available online at: $\mathrm{http}: / / \mathrm{dx} . \mathrm{doi} . \mathrm{org} / 10.1093 / \mathrm{phe} / \mathrm{phs022}$ 
it respects other important ethical principles, such as reciprocity, equality or social justice (Upshur, 2002; Holland, 2007).

The major ethical problem with the behavior-change approach is that it allows and endorses manipulative strategies. We primarily find this problem in strategies like social marketing, and in 'scare campaigns' (Buchanan, 2000). Social marketing is a kind of intervention that uses commercial marketing tools, for the benefit of both the individual (or group) and society (French et al., 2009; Cheng et al., 2011), e.g. using gender and age stereotypes for 'selling' health behavior (Naidoo and Wills, 2005: 164). Marketing tools are often manipulative, in that they influence the individual's wants (Rosenberg's 1 and 4) and beliefs (2) (Pollay, 1986, 2000).11 Appealing to sex or sexiness is one such manipulative strategy. A German advertisement aiming at getting women to visit their gynecologist to check if they are at risk of developing breast cancer, show a 'femme fatale', focusing on her barely covered breasts, with the accompanying text: '75\% of all men first look at a woman's bosom. Your gynecologist should be one of them' (in Loss and Nagel, 2010: 59; author's translation).

Thus, the major ethical problem with manipulative marketing strategies is that they try to make the person do something that she has not herself (actively) chosen-for reasons she is not fully aware of. Thus, it creates inauthentic wants ( 1 and 4 ), as well as installing false beliefs (2), and thus, disregards the right to autonomy (self-determination).

Scare campaigns are no better. Some aim at influencing people's behavior, through pre-reflective emotional reactions, such as associating health hazards with something unpleasant, disgusting or (vaguely) dangerous (Witte and Allen, 2006: Loss and Nagel, 2010; Brülde, 2011a), i.e. they try to manipulate wants ( 1 or 4 ). Others might involve exaggerations and misinformation, especially when trying to meet marketing 'rules', e.g. '[k]eep it short and simple' (Loss and Nagel, 2010: 59; Brülde, 2011a).12 In the latter cases the influence is often cognitive (2), rather than emotional (even if perceived threats due to exaggeration or misinformation are also likely to increase emotional arousal) (Witte and Allen, 2006: 592). A model sometimes used is the health belief model, which (among other things) states that a perceived threat (2) makes the person more likely to act to avoid the threat, and that the more severe the consequences are thought to be (2), the more likely it is that the person takes action (Nutbeam et al., 2010). 'Scare' campaigns might use this model and either exaggerate the susceptibility, e.g. the likelihood of getting HIV if you have unprotected sex, or the perceived severity of the consequences (2), e.g. that smoking makes men impotent (2), in order to make people change their behavior (Brülde, 2011a). Thus, this kind of campaign disregards the right to autonomy through manipulating the person's beliefs system, as well as distorting her wants.

Defenders of the above mentioned strategies might claim that people are not very autonomous in the first place, since all kinds of forces in society influence us to want and do things (Foucault, 1986), and in this case, we might as well 'counter-manipulate' individuals (Holland, 2007: 128, 129). No doubt, the ability for autonomy (self-determination) differs in the population. However, assuming that we are not fully determined by material or social structures, the answer to this problem should

This is a pre-copy-editing, author-produced PDF of an article accepted for publication in Public Health Ethics following peer review. The definitive publisher-authenticated version Tengland, Per-Anders. (2012) Behavior Change or Empowerment: On the Ethics of Health-Promotion Strategies, Public Health Ethics, 5, 140-153, is available online at: http://dx.doi.org/10.1093/phe/phs022 
not be more paternalistic manipulation, but, rather, to strenghen the autonomy of those with less ability for it.

Coercion and manipulation are not very common on the local level, especially not in health promotion. When they occur, we find that the individuals (or group) participating often accept being manipulated or coerced.13 This might, for example, happen in certain kinds of psychotherapy, where the therapist uses 'manipulative' techniques (autonomously) accepted by the individuals participating. One example is to accept hypnotic treatment, e.g. for smoking cessation (Holroyd, 1980). Voluntarily accepted coercion, although rare, is found in cases where individuals ask to be committed to treatment, for, say, alcoholism, drug abuse or a mental disorder (Carroll, 1991; Wild, 2006).

This seems to imply that coercion and manipulation, in these specific cases, are acceptable strategies. No doubt they are, assuming that there are other strategies available to choose from. If the person has few options, we cannot really conclude that the strategy fully respects the right to autonomy.14

\section{Some Measures Risk Causing Harm}

Interventions that are persuasive, manipulative or coercive do not respect the individual's right to autonomy. Some such interventions, e.g. the obligation to wear seat-belts when driving, can be defended, since they constitute minor rights infringements and the harms avoided are substantial. But what if the individual is inadvertently harmed in some other way? Are there behavior-change interventions that lead to situations that are worse than the ills they were designed to alleviate? Improving a person's future health through reducing her quality of life might be such an example. Professionals might try to persuade, coerce or manipulate people into actions or behavior that they on the whole dislike, such as exercising more, giving up smoking, or giving up some of their favorite foods or drinks (Fitzpatrick, 2001: 35 ff.; Holland, 2007: 122).

But a more serious harm might be that of reducing the individual's ability for self-determination (or autonomy), or, similarly, that 'coercive interference' might 'displace individual initiative' (ascribed to J.S. Mill by Powers et al., 2012: 10). Manipulation risks leading to such a result. Marketing strategies are in general manipulative, because they try to induce people to do, or buy, things that they did not originally want, and that they would not have bought or done, had they had more information or sufficient time to deliberate. Employing manipulative techniques in social marketing appears to be counter-productive, as the risk is that the more people are manipulated, the less autonomous they will become. Some reasons for this are that manipulation reduces knowledge (a prerequisite for autonomous choices), through false, skewed or partial information, and that it makes the individual less inclined to critically reflect on the options available (Pollay, 1986, 2000). Note also that marketing in general, appeals to 'vices' such as '[l]ust, sloth, greed and pride' (Mayer, 1961 in Pollay, 1986: 908) and, adds David Buchanan, to 'envy and gluttony' (Buchanan, 2000: 77)-vices that are

This is a pre-copy-editing, author-produced PDF of an article accepted for publication in Public Health Ethics following peer review. The definitive publisher-authenticated version Tengland, Per-Anders. (2012) Behavior Change or Empowerment: On the Ethics of Health-Promotion Strategies, Public Health Ethics, 5, 140-153, is available online at: http://dx.doi.org/10.1093/phe/phs022 
usually not rationally (i.e. autonomously) chosen (Buchanan, 2000). Alluding to vices, and indirectly reinforcing them, thus appears to be a suspect way to lure people into health-related behavior.

Buchanan (2000: 77, 78) provides an example. In a planned campaign to get young men to drink less alcohol, the message to be delivered was that young women find men that drink less more 'sexually attractive'. Thus, such an intervention might have negative health consequences, since the emphasis on the value of sexual attractiveness might lead to more casual sex in these groups of young people, this in turn leading to increases in sexually transmitted diseases and in teenage pregnancies. This is debatable,15 but referring to sex (in this case, a form of 'greed' for more sex) as a motive for reduced drinking may still be seen as questionable, especially since such an appeal to sexuality may also reinforce gender stereotypes, thus compromising other important values and norms (Buchanan, 2000: 77, 78). Marketing companies do not need to use these kinds of stereotypes but they typically do (Wolin, 2003), even if things might be changing for the better (Wolin, 2003). Note that in the USA, the companies used for social marketing are sometimes the same ones as used for ordinary marketing (Buchanan, 2000: 76).

Note, finally, another sort of harm that might be the result of certain behavior-change strategies. Interventions such as social marketing and scare campaigns, and sometimes also 'non-reciprocal' coercion (Upshur, 2002), might erode the trust that people have in authorities (Brülde, 2011a: 224), because some such interventions might appear to be cynical, as they use people as means, and do not treat them as capable, thinking citizens (Buchanan, 2000: 78).

\section{Positive Aspects of Working with Empowerment as a Process}

The empowerment approach avoids the ethical problems found in the behavior-change approach. It fully respects the participating individuals' right to self-determination, since they are completely involved in the problem formulation, the decision process, and the actions undertaken. Moreover, the approach also develops or increases the ability for autonomy, as well as other forms of control, since active participation requires taking or sharing responsibility for what is to be achieved, and for how it is to be achieved. This in turn leads to the development of various kinds of knowledge, skills and 'well-being' (Laverack, 2009; Powers et al., 2012: 9). Groups that participate develop their 'collective autonomy', in that they develop deliberating, reasoning and negotiating skills, and therefore acquire tools for making democratic decisions (Laverack, 2009). Thus, the focus of the approach is first and foremost on the last aspects in Rosenberg's teleological schema, namely, ability (6), and the know-how (5) required by 6 . This may lead to changing beliefs (2) and perhaps also to changing wants (1 or 4$) .16$

How do we justify this emphasis on respecting (the right to) and furthering (the ability for) autonomy (self-determination)? One way is to point to the fact that self-determination is considered a human right (UNO, 1948). But what makes it a human right? Griffin $(2008: 32,33)$ reasons as follows: Personhood is what makes us most distinctly human, and certain things are required for personhood, namely autonomy (i.e. 'choosing one's own path in life'), some degree of welfare, or 'minimum

This is a pre-copy-editing, author-produced PDF of an article accepted for publication in Public Health Ethics following peer review. The definitive publisher-authenticated version Tengland, Per-Anders. (2012) Behavior Change or Empowerment: On the Ethics of Health-Promotion Strategies, Public Health Ethics, 5, 140-153, is available online at: http://dx.doi.org/10.1093/phe/phs022 
provision' (i.e. a minimum of 'resources and capacities') and liberty (i.e. not being forcibly stopped from pursuing one's life plans). Autonomy as discussed in this article includes both Griffin's account of autonomy (choosing) and opportunity (being able to act), i.e. freedom. Empowerment as a state (having control over life and health), then, to a great extent overlaps with the requirements for Griffin's idea of personhood. Empowerment as a process respects people's right to selfdetermination, and therefore also their personhood.

But how is autonomy (self-determination) linked to health? The central idea is that (in general) the more autonomous a person is, the more likely it is that she stays healthy, and this is vindicated by the research. Control over the determinants of health (including, as we have seen, 'resources and capacities') is, in general, positive for health (Karasek and Theorell, 1992; Marmot and Wilkinson, 1999; Marmot, 2004; Wilkinson and Picket, 2010). This might involve behavior change, e.g. exercising more, but behavior change (in itself) does not always lead to better control or increased autonomy.

Finally, do the empowerment strategies aimed at creating more control over health also reduce inequalitities in health? When it comes to our primary concern, local interventions, they do decrease inequalities, since they primarily target vulnerable groups, i.e. those that have poorer health and worse living conditions than other groups (Freire, 1972; Laverack, 2009: $80 \mathrm{ff}$.). On the whole, then, empowerment projects will decrease inequalitities.

\section{Possible Problems of Working with Empowerment as a Process}

There are a number of concerns that have been raised over the years about the feasibility of the empowerment approach. Critics have claimed that professionals cannot, and should not, reduce their power or control over projects, that the empowerment approach imposes its 'method' and goals on the participants, and, therefore, does not live up to its own standards, and finally, that the approach is more time consuming and therefore also risks costing more.

\section{The Limits of Reduced Professional Control over the Process}

Do we really want professionals to reduce their power over the process? Could that not even be dangerous? What if the individual, or group, wants to initiate projects where the means used are believed by the professional to be mistaken, counterproductive, or even harmful, or that might not be expected to lead to better health for the individual or for the group (Braunack-Mayer and Louise, 2008: 6)?

There are limits to what professionals can and are legally and morally allowed to do. A professional should only participate in projects that are considered possible, reasonably effective, legal (if there are no strong moral reasons for illegal actions) and morally defensible (Tengland, 2011). The professional is part of the project, and should therefore also have a say in the matters discussed and decided on, and she always has the option to refrain from continuing a project (on the grounds stated above). This should not, however, be taken as a professional's way to, in fact, impose her will. Good arguments have to be provided for refusing to accept a project not found feasible or morally

This is a pre-copy-editing, author-produced PDF of an article accepted for publication in Public Health Ethics following peer review. The definitive publisher-authenticated version Tengland, Per-Anders. (2012) Behavior Change or Empowerment: On the Ethics of Health-Promotion Strategies, Public Health Ethics, 5, 140-153, is available online at: http://dx.doi.org/10.1093/phe/phs022 
acceptable. Furthermore, many professionals will not work at all with the empowerment approach, since it is not possible to do so in their field; this, for example, goes for (most) police officers, fire fighters, judges and emergency ward staff.

\section{The Professional Can Never Refrain from Exerting Power}

An important question, which has been much discussed, concerns whether professionals can refrain from using their power in empowerment projects (Buchanan, 2000: 80; Holland, 2007: 129). They should, after all, be 'experts' on how to achieve an empowering process (Lietaer, 1998). Is it possible then, to work in the envisioned way, without power (in a problematic sense) entering at some point? The question hinges upon what we mean by 'power' and the ethical implications of different aspects of power.

Clearly, a professional will have an influence on every project she participates in. However, that cannot be seen as a problem in itself. It depends on the kind of influence involved, i.e. if it is morally legitimate or illegitimate. Giving advice when asked, cannot be seen as a problem, not even giving (matter-of-fact) arguments for certain choices. The professional is, after all, collaborating with the people facilitated and is, thus, part of the process. What is morally problematic, as we have seen, is persuasion, manipulation or (covert or overt) coercion, i.e. making participants do what they have not consciously/deliberately and freely chosen. For the professional to have an agenda, other than facilitating increased control over life and health, would contradict the definition (taken for granted in this article) of empowerment as a process, i.e process and goals should harmonize (Tengland, 2008). In conclusion, it is hard to see that the professional necessarily has to exert power over the other participants (in any problematic way). That some professionals fail to fully live up to the demanding requirements of the empowerment approach can only be expected, especially since few schools of public health or health promotion train students in it (Buchanan, 2000: $144 \mathrm{ff}$.).

Furthermore, on the whole, the professional is usually more empowered than the average participating individual, group, or community member. For example, she has more knowledge about relevant fields of professional practice. Again, this should not necessarily be a problem, as long as all people involved are respected as equals, and where everyone's 'expertise' is taken into account in the project. The participating members have experiences and knowledge that the professional lacks, e.g. about their own concrete problems and living conditions. In the same way, the professional's knowledge should count as an available asset. Thus, what we will end up with is 'group power' (Allen, 1998), where all members contribute and strengthen the collective power of the group.

\section{Autonomy and Control as Predetermined Goals}

It has, so far, been taken for granted that the right to (and increase in) autonomy and control is something positive and that people should (be invited to) participate in decisions that affect their lives. Using this strategy and furthering these aims might also be seen as paternalistic, since the agenda is decided beforehand by the professionals (Braunack-Mayer and Louise, 2008: 6). Thus, when using the empowerment strategy, the professionals can still be seen as having power over the

This is a pre-copy-editing, author-produced PDF of an article accepted for publication in Public Health Ethics following peer review. The definitive publisher-authenticated version Tengland, Per-Anders. (2012) Behavior Change or Empowerment: On the Ethics of Health-Promotion Strategies, Public Health Ethics, 5, 140-153, is available online at: http://dx.doi.org/10.1093/phe/phs022 
change process and its aims. True, but is this really a problem? Every intervention has to rely on some ethical foundation, and all are not equally acceptable. As we have already seen, there is a very strong Western liberal tradition that people should be permitted, and encouraged, to govern themselves, and this is tied to the personhood and dignity of the individual (Mill, 1859; Nordenfelt, 2004; Griffin, 2008).17 Just as we refuse to count the abolition of democracy as a valid goal in a democracy, even if it would lead to better health, or increased quality of life, we refuse to count disregarding the right to autonomy or self-determination as a legitimate consequence of public policy, with certain exceptions (already mentioned).18

\section{It Takes Longer to Achieve the Goals}

A final critical point has to do with the expected fact that empowerment interventions are more time consuming (Nutbeam et al., 2010). The fact that people have to gather and deliberate on the goals and means, before anything can get off the ground, is a strong indication that the assumption is correct (Laverack, 2009). It is well known that psychotherapy, which is not 'goal-directed' or 'problem-focused' is expected to take longer (Mearns, 2004). Compare, for example, the very specific attempt to get rid of an obsession (cognitive-behavioral therapy) with the exploration of a childhood trauma where the child was abandoned by her mother (person-centered therapy). The same thing goes for participatory research strategies (Mclntyre, 2008), i.e. they take longer than many other kinds of research strategies.

If projects take longer, this also means that they might be more costly. The professionals need to stay longer in the field, meeting with the people involved. The time frame basically depends on two things. First, it has to do with what goals are chosen by the individual or group involved, and with the means needed for attaining these goals. The more ambitious the goals are, the more likely it is that they will take time to achieve. Second, it also has to do with the level of awareness, knowledge, skills and autonomy in the individual, group or community that is involved. The lower the initial competence is, the more likely it is that the project will take time.19 There are other factors that might also influence the time it takes. Conflicting interests within the group or community might have to be dealt with, and the goals chosen might be in conflict with the interests of (powerful) groups in society.

The principle of cost-effectiveness states that we should choose to maximize the outcome (health) in relation to what we spend (Brülde, 2011b). In general, the behavior-change projects are more narrow in scope, since they often focus on one kind of risk behavior and therefore seem more cost-effective. The problem is, however, that it is difficult to compare outcomes if the targeted health goals are different, which they most likely are, because, in empowerment projects, the specific health goals will be chosen by the group in question, and we cannot know beforehand (exactly) what they will be. It is then, more or less impossible to compare (in terms of cost-effectiveness) behavior-change projects, such as a smoking cessation group (1, in Rosenberg's model), with empowerment projects, such as a community-intervention project where the communal decision is to try to get rid of drug

This is a pre-copy-editing, author-produced PDF of an article accepted for publication in Public Health Ethics following peer review. The definitive publisher-authenticated version Tengland, Per-Anders. (2012) Behavior Change or Empowerment: On the Ethics of Health-Promotion Strategies, Public Health Ethics, 5, 140-153, is available online at: http://dx.doi.org/10.1093/phe/phs022 
dealers in their neighbourhood (e.g. reducing the opportunity for kids to try drugs, 7 in Rosenberg's model). But even if we, on comparing typical intervention designs, grant that behavior-change projects might be more cost-effective than empowerment interventions, it is only one of the several criteria for success, and we can, as we have seen, defend empowerment interventions on other, moral, grounds.

\section{Behavior Change and Empowerment: Reaching Their Targets?}

What about the success of behavior change and empowerment of interventions? Many projects whose goal was to change people's behavior and lifelstyle in a more health-enhancing way have been tried over the years. Coercive, top-down, legislative interventions, such as the requirement to wear seat-belts and crash-helmets, have often succeeded (Pellmer and Wramner, 2009), as have some fiscal policies, such as taxing alcohol highly, which is the case in the Nordic countries (Babor et al. 2003). But the results of lifestyle projects are more mixed. Some have succeeded, or have partly succeeded (Snyder and Hamilton, 2002; Glanz et al., 2008), while others have failed (SBU, 1997; Beaglehole and Bonita, 2004: 263; Baum 2008: 474). A major review conducted by Swedish researchers who studied eight large-scale (scientifically well-designed) top-down behavior-change projects showed that the effects of these projects were moderate or nonexistent (SBU, 1997). The authors of one of the original studies concluded that the 'net improvements... that can be attributed to the MHHP intervention were modest, generally of limited duration and usually within chance levels" (in SBU, 1997: 122). Glanz et al. come to a similar conclusion (2008). The results of many major behavior-change projects 'cast doubt on the presumed effectiveness of population-based intervention strategies over the long term' (Glanz et al., 2008: 16; see also Syme, 1996: 21, 22; Baum, 2008: 460 ff.; Laverack, 2009: 117; Syme and Ritterman, 2009: 4, 5).

This is one reason why strategies have changed over the last years, focusing more on changing the environment, such as in "healthy cities" projects, rather than focusing straight-forwardly on behaviors and their immediate internal determinants (Baum, 2008: 531). This is partly the result of the Ottawa Charter for Health Promotion, where focus was moved to the social determinants of health (WHO, 1986). This change has been accompanied by an emphasis on individual and community participation and empowerment strategies (WHO, 1986). Further emphasis on the determinants of health within the WHO confirms this trend (WHO, 2008). These kinds of projects and policies move us closer to the empowerment strategy, since they often involve creating opportunities (WHO, 2008).

Concerning local projects, it is hard to give a general answer. Many behavior-change projects report some success (Snyder and Hamilton, 2002; Glanz et al., 2008; Nutbeam et al., 2010), which means that it might, for this reason, be premature to abandon them. And as mentioned, some projects of this kind might succeed also on empowerment terms, e.g. increasing health-related knowledge, which might increase control over health-related factors. An interesting development within healthcare, traditionally very behavior-change oriented, is the move towards more participatory strategies,

This is a pre-copy-editing, author-produced PDF of an article accepted for publication in Public Health Ethics following peer review. The definitive publisher-authenticated version Tengland, Per-Anders. (2012) Behavior Change or Empowerment: On the Ethics of Health-Promotion Strategies, Public Health Ethics, 5, 140-153, is available online at: http://dx.doi.org/10.1093/phe/phs022 
such as 'motivational interviewing' (Miller and Rollnick, 2002), used, for example, to achieve smoking cessation (Schinitzky and Kub, 2001).

A number of local projects, likewise, show support for empowerment as a process. A major literature review of research concerning various kinds of empowerment projects, made by Nina Wallerstein for the WHO in 2006, showed that the approach was successful in a number of health-related areas, such as maternal health, HIV reduction, mental illness reduction, building self-confidence in young people, and child health, to mention just a few areas (Wallerstein, 2006).

Several other authors support Wallerstein's (2006: 5) conclusion about the value of empowerment and of 'authentic participation'. Tones and Green (2004: 39), for example, advocate the empowerment approach, not only for its 'ideological soundness', but also for its 'practical effectiveness'. Laverack suggests that public health programs 'will only be successful if they can maintain a high degree of participation' (Laverack, 2009: 121), and that in order to achieve sustainable change we have to combine top-down agendas, primarily those addressing socioeconomic inequalities and bottom-up (local) ones (Labonté and Laverack, 2008).

Involving people may have some advantages. One is that the aims of the project will be more appropriate, because people in the communities are more aware of what their 'wider' problems are (i.e. have knowledge about the causes of their health problems, such as unemployment or lack of education), and they will therefore choose to try to change what they experience as the more important aspects of their situation-aspects that professionals, civil servants and politicians often know less about (Rogers 1961, 1977; Freire 1972; Laverack, 2009; Syme and Ritterman, 2009). Second, some authors claim that projects that include 'real' participation of those involved, i.e. when people are engaged in what is important to them, are more likely to succeed, and that the effects are more likely to be sustained (Beaglehole and Bonita, 2004: 262, 263; Tones and Green, 2004; Baum, 2008; Laverack, 2009; Syme and Ritterman, 2009).

This does not prove, however, that on the whole empowerment projects succeed more than behavior-change projects, but it indicates that there is a general trend toward more participation, perhaps for other reasons than success, such as moral ones.

\section{Conclusions}

This article presents a comparison between two kinds of approaches in health promotion, namely behavior change and empowerment. It tries to show why we should prefer empowerment methods, rather than work with persuasive, manipulative or coercive tools to change specific behaviors.

Some behavior-change projects are relatively unproblematic, and might even empower peopleeven if they risk increasing inequality in health. Furthermore, some interventions might be legitimately coercive. But we have also seen that behavior-change projects can be morally

This is a pre-copy-editing, author-produced PDF of an article accepted for publication in Public Health Ethics following peer review. The definitive publisher-authenticated version Tengland, Per-Anders. (2012) Behavior Change or Empowerment: On the Ethics of Health-Promotion Strategies, Public Health Ethics, 5, 140-153, is available online at: http://dx.doi.org/10.1093/phe/phs022 
problematic for several reasons, e.g. in that they do not sufficiently respect, nor further, the autonomy (or freedom) of the individuals involved, or respect their dignity, and in that they risk increasing health inequalities. However, we have to acknowledge that some people participate in behavior-change projects that they have chosen, and where the goals and means are determined beforehand. The major problem in these cases is rather that the kinds of interventions available may be limited, and that they focus narrowly on behavior change and not on a change of life situation, which might better address the 'real' health problem, i.e. the wider causes of the problem, and not just its symptoms.

Local interventions are often more morally delicate than top-down ones, since they involve meeting people 'eye-to-eye', and ususally target lifestyle changes, such as choice of foods and drinks, smoking, sexual behavior or physical activity, i.e. issues more closely related to the identity of individuals, and (usually) more important for their quality of life.

Empowerment, as I have tried to show, can handle most of the problems of the behavior-change approach. It respects the right to autonomy, as well as furthering autonomy as ability, it respects the person's dignity, and it reduces inequalities. Empowerment strategies do, of course, fail at times and they can be realized to a larger or lesser extent. The general point made, however, is that, on the whole, the empowerment approach is preferable to the behavior-change approach.

\section{Acknowledgements}

I would like to thank Bengt Brülde, Glenn Laverack, Martin Berzell, Katarina Graah-Hagelbäck, my colleagues at the department of Public Health, Health and Society, at Malmö University and the two anonymous reviewers for valuable comments on earlier versions of this article.

\section{Footnotes}

$\triangleleft 1$. One exception is vaccination programs that do something to people's bodies, namely strengthen their immune system. Another one is putting fluoride in the drinking water to strengthen the enamel of people's teeth, and thereby increasing dental health of the population.

«2. Empowerment, at least, is a goal in many other professional contexts, e.g. social work and education.

43 . In an earlier article, I have argued that the goal should rather be quality-of-life-related health (Tengland, 2007), because health is primarily an instrumental goal and, therefore, health gains that do not lead to a better life do not appear worthwhile trying to achieve. The distinction is not, however, important for this article and will not be used.

44 . Note that the two categories 'health-related behavior' and 'lifestyle' do not seem to overlap fully. 'Health-related behavior' appears to be a somewhat broader notion than 'lifestyle'. The latter notion

This is a pre-copy-editing, author-produced PDF of an article accepted for publication in Public Health Ethics following peer review. The definitive publisher-authenticated version Tengland, Per-Anders. (2012) Behavior Change or Empowerment: On the Ethics of Health-Promotion Strategies, Public Health Ethics, 5, 140-153, is available online at: http://dx.doi.org/10.1093/phe/phs022 
usually covers choice of food and drinks, smoking and drug use, sex activities, sunbathing and physical activities, whereas the former notion also includes issues such as wearing seat-belts and crash-helmets, hand washing, using bed nets, taking vitamin pills, and mammography and vaccinations. Lifestyle matters seem more important to people, and the debate about them more 'heated', perhaps because they lie closer to the identity of the individual or group, and/or perhaps because they are more relevant for people's quality of life. However, it is hard to make the distinction precise, and it will not be used in this article.

45 . This article does not discuss some of the contemporary changes in health promotion where more and more attention is directed toward the environment (Baum, 2008: 465), primarily because this risks blurring the distinction made in the article between behavior change and empowerment.

46. That is, given that the 'premises' are fulfilled, the agent is rationally obliged to act. The syllogism, however, allows irrationality in one or several of its premises. A person might 'act rationally' on irrational beliefs or on irrational wants. The explanation of the action is still valid.

47. Autonomy is always 'contextual', i.e. choices are made within a social and cultural structure that limits the ones available (or possible to pursue), conceptually and empirically. However, in our globalized world these choices can be quite numerous and diverse.

48 . Dignity, here, more or less refers to what Nordenfelt (2004: 75) has called 'dignity of identity', i.e. the dignity attached to our 'integrity and identity as human beings', which is closely related to selfrespect and feelings of worth.

49. The assumption here is that this information is not asked for, nor related to the problem that the individual sought help for.

$\triangleleft 10$. There is a difference between getting (opportunistic) information concerning e.g. a suspected melanoma, or concerning the risks related to alcohol consumption. The more serious the potential problem, the less controversial this kind of information. We can assume that most people want to be informed about serious and immediate health risks, and in cases where they do not, the positive consequences of the information clearly outweigh the negative ones.

$\longleftrightarrow 11$. If they are purely informative, or only change the environment, they will be ignored here.

$\triangleleft 12$. Few campaigns use straightforward lies, as many countries, like the USA and Sweden, have laws against using lies in advertising (Brülde, 2011a: 225).

$\triangleleft 13$. The point was made by Bengt Brülde (personal communication, February 2012).

$\triangleleft 14$. Coercion in the (stronger) sense of using force or compulsion, sometimes regarded as necessary for some public health measures, is less common in the health-promotion context. Compulsive measures, such as forcing people to leave their homes in emergencies (e.g. flooding, forest fires), or

This is a pre-copy-editing, author-produced PDF of an article accepted for publication in Public Health Ethics following peer review. The definitive publisher-authenticated version Tengland, Per-Anders. (2012) Behavior Change or Empowerment: On the Ethics of Health-Promotion Strategies, Public Health Ethics, 5, 140-153, is available online at: http://dx.doi.org/10.1093/phe/phs022 
imposing quarantine or isolation on people or groups in cases of serious pandemics (Verweij, 2011), do not specifically relate to behavior or behavior change.

415 . Reduced alcohol intake might make the person less, rather than more, likely to engage in casual sex. The point was made by Martin Berzell (personal communication, March 2012).

$\triangleleft 16$. It should be added that the empowerment approach is compatible with the insight that some people do not want to participate actively, or decide on certain issues. For certain kinds of projects such a standpoint must be respected, especially if it rests on an autonomous choice. Any such refusal to participate should be a strong incentive to try to find out why this is the case.

$\triangleleft 17$. The relativist idea that these are Western ideals and not applicable to other cultures has been refuted by a number of thinkers, e.g. by Martha Nussbaum (2011: $101 \mathrm{ff}$. ).

418 . The best reason for not respecting (the right to) autonomy is future 'substantive autonomy' (i.e. autonomy as ability) (J. Raz, in Braunack-Mayer and Louise, 2008: 6). Also see Nikku (1997).

419. Personal communication with Glenn Laverack (25 August 2010).

\section{References}

Allen A. Rethinking Power. Hypatias 1998;13:21-40.

Babor T, Caetano R, Casswell S, Edwards G, Giesbrecht N, Graham K, Grube J, Grunewald P, Hill L, Holder H, Homel R, Livingston M, Österberg E, Rehm J, Room R, Rossow I. Alcohol: No Ordinary Commodity - Research and Public Policy. Oxford: Oxford University Press; 2003.

Bandura A. Self-Efficacy Mechanism in Human Agency. American Psychologist 1982;37:122-147.

Baum F. The New Public Health. 3rd edn. Oxford: Oxford University Press; 2008.

Bayer R, Gostin L O, Jennings B, Steinbock B, editors. Public Health Ethics. Theory, Policy, and Practice. Oxford: Oxford University Press; 2007.

Beaglehole R, Bonita R. Public Health at the Crossroads. Cambridge: Cambridge University Press; 2004.

Braunack-Mayer A, Louise J. The Ethics of Community Empowerment: Tensions in Health Promotion Theory and Practice. IUHPE - Promotion \& Education 2008;15:5-8.

Brülde B. Vilka medel är acceptabla i jakten på en bättre folkhälsa [What Means are Acceptable in the Pursuit of Better Public Health]. In: BrüldeB, editor. Folkhälsoarbetets etik [The Ethics of Public Health Work]. Lund: Studentlitteratur; 2011a. p. 207-233.

This is a pre-copy-editing, author-produced PDF of an article accepted for publication in Public Health Ethics following peer review. The definitive publisher-authenticated version Tengland, Per-Anders. (2012) Behavior Change or Empowerment: On the Ethics of Health-Promotion Strategies, Public Health Ethics, 5, 140-153, is available online at: $\mathrm{http}: / / \mathrm{dx}$.doi.org/10.1093/phe/phs022 
Brülde B. Health, Disease, and the Goals of Public Health. In: DawsonA, editor. Public Health Ethics. Cambridge: Cambridge University Press; 2011b. p. 20-47.

Buchanan D. An Ethic for Health Promotion. Oxford: Oxford University Press; 2000.

Carroll J S. Consent to Mental Health Treatment: A Theoretical Analysis of Coercion, Freedom and Control. Behavior Sciences and the Law 1991;9:129-142.

Cheng $\mathrm{H}$, Kotler P, Lee N R, editors. Social Marketing for Public Health: Global Trends and Success Stories. Sudbury, MA: Jones and Bartlett; 2011.

Craig G, Majo M, Popple K, Shaw M, Taylor M. The Community Development Reader. History, Themes and Issues. Briston: The Policy Press; 2011.

Daniels N. Equity and Population Health: Toward a Broader Bioethics Agenda. In: DawsonA, editor. Public Health Ethics. Cambridge: Cambridge University Press; 2011. p. 191-210.

Downie R S, Tannahill C, Tannahill A. Health Promotion: Models and Values. Oxford: Oxford University Press; 1996.

Earl S, O'Donnell T. The Factors that Influence Health. In: EarleS, LloydC E, SidellM, SpurrS, editors. Theory and Research in Promoting Public Health. London: Sage; 2007. p. 67-100.

Finnegan J R, Viswanath K. Communication Theory and Health Behavior Change: The Media Studies Framework. In: GlanzK, RimerB K, ViswanathK, editors. Health Behavior and Health Education: Theory, Research, and Practice. 4th edn. San Francisco: Jossey-Bass; 2008. p. 364-387.

Fitzpatrick M. The Tyranny of Health: Doctors and the Regulation of Lifestyle. London: Routledge; 2001.

Foucault M. Michel Foucault: Power/Knowledge. GordonC, editor. Brighton: Harvester Press; 1986.

Freire P. Pedagogik för förtryckta [Pedagogy of the Oppressed]. Stockholm: Gummessons; 1972.

French J B-S, C, McVey D, Merritt R. Social Marketing and Public Health: Theory and practice. Oxford: Oxford UP; 2009.

Glanz K, Lewis F M, Rimer B K, editors. Health Behavior and Health Education: Theory, Research, and Practice. 2nd edn. San Francisco: Jossey-Bass; 1997.

Glanz K, Rimer B K, Viswanath K, editors. Health Behavior and Health Education: Theory, Research, and Practice. 4th edn. San Francisco: Jossey-Bass; 2008.

Grier S, Bryant C A. Social Marketing in Public Health. Annual Review of Public Health 2005;26:319339.

This is a pre-copy-editing, author-produced PDF of an article accepted for publication in Public Health Ethics following peer review. The definitive publisher-authenticated version Tengland, Per-Anders. (2012) Behavior Change or Empowerment: On the Ethics of Health-Promotion Strategies, Public Health Ethics, 5, 140-153, is available online at: http://dx.doi.org/10.1093/phe/phs022 
Griffin J. On Human Rights. Oxford: Oxford University Press; 2008.

Holland S. Public Health Ethics. Cambridge: Polity; 2007.

Holroyd J. Hypnosis Treatment for Smoking: An Evaluative Review. International Journal of Clinical and Experimental Hypnosis 1980;28:341-357.

Karasek R, Theorell T. Healthy Work: Stress, Productivity, and the Reconstruction of Working Life. New York: Basic Books; 1992.

Labonté R, Laverack G. Health Promotion in Action: From Local to Global Empowerment. Basingstoke: Palgrave Macmillan; 2008.

Lalond M. A New Perspective on the Health of Canadians: A Working Document Government of Canada [Internet]. Ottawa; 1974. available from: http://www.phac-aspc.gc.ca/ph-sp/pdf/perspecteng.pdf§ [accessed 16 August 2012].

Laverack G. Public Health, Power and Empowerment. 2nd edn. Basingstoke: Palgrave MacMillan; 2009.

Lietaer G. From Non-Directive to Experiential. In: ThornB, LambersE, editors. Person-Centred Therapy: A European Perspective. London: Sage; 1998. p. 62-73.

Loss J, Nagel E. Social Marketing - Verführung zum gesundheitsbewussten Verhalten? [Social Marketing - Seduction with the Aim of Healthy Behavior?]. Gesundheitswesen 2010;72:54-62.

Maibach E, Parrott R L. Designing Health Messages. Approches from Communication Theory and Public Health Practice. London: Sage; 1995.

Marmot M. The Status Syndrome. How Your Social Standing Directly Affects Your Health. London: Bloomsbury Publishing; 2004.

Marmot M, Wilkinson R. The Social Determinants of Health. Oxford: Oxford University Press; 1999.

McIntyre A. Participatory Action Research. London: Sage; 2008.

Mearns D. Problem-Centered is not Person-Centered. Person Centered and Experiential Psychotherapy 2004;3:88-101.

Mill J S. On liberty and Utilitarianism. London: Everyman's Library; 1859. 1992.

Miller W R, Rollnick S. Motivational Interviewing. Preparing People for Change. New York: The Guilford Press; 2002.

This is a pre-copy-editing, author-produced PDF of an article accepted for publication in Public Health Ethics following peer review. The definitive publisher-authenticated version Tengland, Per-Anders. (2012) Behavior Change or Empowerment: On the Ethics of Health-Promotion Strategies, Public Health Ethics, 5, 140-153, is available online at: http://dx.doi.org/10.1093/phe/phs022 
Naidoo J, Wills J. Public Health and Health Promotion. Developing practice. 2nd edn. Edinburgh: Baillière Tindall; 2005.

Nikku N. Informative Paternalism: Studies in the Ethics of Promoting and Predicting Health. Vol. 155. Dissertation. Linköping Studies in Arts and Science; 1997.

Nordenfelt L. Towards a Theory of Health Promotion: A Logical Analysis. 1991. Health Service Studies, 5, Link $>$ Collaborating Centre for WHO programmes on hospitals and other health institutions, Linköping, Sweden.

Nordenfelt L. The Varieties of Dignity. Health Care Analysis 2004;12:69-81.

Nussbaum M. Creating Capatilities: The Human Development Approach. Cambridge, MA: The Belknap Press of Harvard University Press; 2011.

Nutbeam D, Harris E, Wise M. Theory in a Nutshell: A Practical Guide to Health Promotion Theories. North Ryde: McGraw-Hill; 2010.

Pellmer K, Wramner B. Grundläggande folkhälsovetenskap [Basic Public Health]. Stockholm: Liber; 2009.

Pollay R W. The Distorted Mirror: Reflections on the Unintended Consequences of Advertising. Journal of Marketing 1986;50:18-36.

Pollay R W. How Cigarette Advertising Works. Rich Imagery and Poor Information, History of Advertising Archives [Internet]. Vancouver, Canada: Faculty of Commerce, UBC; 2000. available from: http://www.smoke-free.ca/defacto/D057-Pollay-HowCigaretteAdvertisingWorks.pdf [accessed 24 July 2012].

Powers M, Faden R, Saghai Y. Liberty, Mill and the Framework of Public Health Ethics. Public Health Ethics 2012;5:6-15.

Ringer F. Max Weber's Methodology. The Unification of the Cultural and Social Sciences. Cambridge, MA: Harvard University Press; 1997.

Rissel C. Empowerment: The Holy Grail of Health Promotion? Health Promotion International 1994;9:39-47.

Rogers C. On Becoming a Person. Boston: Houghton Mifflin; 1961.

Rogers C. Carl Rogers on Personal Power. New York: Delacorte; 1977.

Rosenberg A. Philosophy of Social Science. Boulder, CO: Westview press; 2008.

This is a pre-copy-editing, author-produced PDF of an article accepted for publication in Public Health Ethics following peer review. The definitive publisher-authenticated version Tengland, Per-Anders. (2012) Behavior Change or Empowerment: On the Ethics of Health-Promotion Strategies, Public Health Ethics, 5, 140-153, is available online at: http://dx.doi.org/10.1093/phe/phs022 
SBU. Att förebygga sjukdom i hjärta och kärl genom befolkningsinriktade program - en systematisk litteraturöversikt [To Prevent Cardiovascular Disease Through Public Programs-A Systamatic Literature Review]. Stockholm: SBU; 1997. (Statens beredning för utvärdering av medicinsk metodik [The government drafting committee for evaluations of methods in medicine]).

Schinitzky H E, Kub J. The Art of Motivating Behavior Change: The Use of Motivational Interviewing to Promote Health. Public Health Nursing 2001;18:178-185.

Snyder L B, Hamilton M A. A Meta-Analysis of U.S. Health Campaign Effects on Behavior Change in the U.S. In: HornikR C, editor. Public Health Communication: Evidence for Behavior Change. Mahwah, New Jersey: Lawrence Erlbaum Associates Publishers; 2002. p. 357-383.

Starrin B. Empowerment som tankemodell [Empowerment as a Conceptual Model]. In: ForsbergE, StarrinB, editors. Frigörande kraft - empowerment som modell i skola, omsorg och arbetsliv [A Liberating Force - Empowerment as a Model in Schools, Care, and Working Life]. Göteborg: Gothia; 1997.

Syme S L. To Prevent Disease. We Need a New Approach. In: BlaneD, BrunnerE, WilkinsonR G, editors. Health and Social Organisation. London: Routledge; 1996.

Search Google Scholar

Syme S L, Ritterman M L. The Importance of Community Development for Health and Well-Being. Community Development: Investment Review 2009;5:1-13.

Tengland P-A. Empowerment: A Goal or a Means for Health Promotion? Medicine, Health Care and Philosophy 2007;10:197-207.

Tengland P-A. Empowerment: A Conceptual Discussion. Health Care Analysis 2008;16:77-96.

Tengland P-A. Health Promotion and Disease prevention: Logically Different Conceptions? Health Care Analysis 2010;18:323-341.

Tengland P-A. Empowerment och etik i folkhälsoarbete [Empowerment and Ethics in Public Health work]. In: BrüldeB, editor. Folkhälsoarbetets etik [The Ethics of Public Health Work]. Lund:

Studentlitteratur; 2011. p. 227-259.

Thaler R H, Sunstein C R. Nudge. Improving Decisions About Health, Wealth and Happiness. New Haven: Yale University Press; 2008.

Tones K, Green J. Health Promotion. Planning and Strategies. London: Sage; 2004.

UNO. The Universal Declarations of Human Rights. 1948. New York. Available from: http://www.un.org/en/documents/udhr/ [accessed 27 December 2011].

This is a pre-copy-editing, author-produced PDF of an article accepted for publication in Public Health Ethics following peer review. The definitive publisher-authenticated version Tengland, Per-Anders. (2012) Behavior Change or Empowerment: On the Ethics of Health-Promotion Strategies, Public Health Ethics, 5, 140-153, is available online at: $\mathrm{http}: / / \mathrm{dx}$.doi.org/10.1093/phe/phs022 
Upshur R E G. Principles for the Justification of Public Health Intervention. Canadian Journal of Public Health 2002;93:101-103.

Verweij M. Infectious Disease Control. In: DawsonA, editor. Public Health Ethics. Cambridge: Cambridge University Press; 2011. p. 100-117.

Verweij M, Dawson A. The Meaning of 'Public' in Public Health. In: DawsonA, VerweijM, editors. Ethics, Prevention and Public Health. Oxford: Oxford University Press; 2007. p. 13-29.

Wallerstein N. What is the Evidence on Effectiveness of Empowerment to Improve Health? Copenhagen: WHO; 2006. Regional Office for Europe. Health Evidence Network report, available from: http://www.euro.who.int/_data/assets/pdf_file/0010/74656/E88086.pdf. [accessed 16 August 2012].

Wallerstein N, Bernstein E. Empowerment Education: Freire's Ideas Adapted to Health Education. Health Education Quarterly 1988;15:379-394.

WHO. Ottawa Charter for Health Promotion. Geneva: WHO; 1986.

WHO. Closing the Gap in a Generation: Health Equity Trough Action on the Social Determinants of Health. Geneva: WHO; 2008.

Wild T C. Social Control and Coercion in Addiction Treatment: Towards Evidence-Based Policy and Practice. Addiction 2006;101:40-49.

Wilkinson R G, Picket K. The Spirit Level. Why equality is better for everyone. London: Penguin; 2010.

Wilson J. Health Inequities. In: DawsonA, editor. Public Health Ethics. Cambridge: Cambridge University Press; 2011. p. 211-230.

Witte K, Allen M. A Meta-Analysis of Fear Appeals: Implications for Effective Public Health Campaigns. Health Education and Behavior 2006;27:591-615.

Wolin L D. Gender Issues in Advertising-An Oversight Synthesis of Research 1970-2002. Journal of Advertising Research 2003;43:111-129.

Wrong D. Power: Its Forms, Bases and Uses. New Brunswick: Transaction; 2004.

This is a pre-copy-editing, author-produced PDF of an article accepted for publication in Public Health Ethics following peer review. The definitive publisher-authenticated version Tengland, Per-Anders. (2012) Behavior Change or Empowerment: On the Ethics of Health-Promotion Strategies, Public Health Ethics, 5, 140-153, is available online at: http://dx.doi.org/10.1093/phe/phs022 